\begin{tabular}{|c|c|c|c|}
\hline \multirow{3}{*}{$\begin{array}{r}\text { Case Reports in } \\
\text { Gastroenterology }\end{array}$} & \multicolumn{2}{|c|}{ Case Rep Gastroenterol 2019;13:25-31 } & \multirow[b]{2}{*}{$\begin{array}{l}\text { Karger } \\
\text { Open'access }\end{array}$} \\
\hline & $\begin{array}{l}\text { DOI: } 10.1159 / 000496385 \\
\text { Published online: January 16, } 2019\end{array}$ & $\begin{array}{l}\text { (c) } 2019 \text { The Author(s) } \\
\text { Published by S. Karger AG, Basel } \\
\text { www.karger.com/crg }\end{array}$ & \\
\hline & $\begin{array}{l}\text { This article is licensed under the } \\
\text { International License (CC BY-NC) } \\
\text { Usage and distribution for commer }\end{array}$ & $\begin{array}{l}\text { nons Attribution-NonCommerci } \\
\text { ger.com/Services/OpenAccessLic } \\
\text { uires written permission. }\end{array}$ & \\
\hline
\end{tabular}

\title{
Acute Esophageal Necrosis: A View in the Dark
}

\author{
Hafiz Khan ${ }^{\mathrm{a}} \quad$ Moiz Ahmed $^{\mathrm{b}}$ Magda Daoud $^{\mathrm{a}} \quad$ Jobin Philipose $^{\mathrm{c}}$ \\ Saba Ahmed ${ }^{c}$ Liliane Deeb ${ }^{a}$ \\ aDepartment of Gastroenterology, Staten Island University Hospital, Northwell Health, \\ Staten Island, NY, USA; bepartment of Gastroenterology, Mount Sinai School of \\ Medicine, Elmhurst Hospital Center, Elmhurst, NY, USA; 'Department of Internal Medicine, \\ Staten Island University Hospital, Northwell Health, Staten Island, NY, USA
}

\section{Keywords}

Esophageal necrosis · Gastrointestinal bleeding

\begin{abstract}
Acute esophageal necrosis (AEN), also known as Gurvits syndrome, black esophagus, or acute necrotizing esophagitis, is a rare clinical entity and an unusual reason for upper gastrointestinal bleeding. It is typically described in critically ill patients with multiple medical conditions, arising from a combination of ischemic insult to the esophageal mucosa due to low-flow vascular states, corrosive injury caused by reflux of acid and pepsin, and decreased function of the mucosal barrier systems and reparative mechanisms as occurs in malnourished and debilitated physical states. Patients with AEN tend to be older men, as medical comorbidities including vascular disease, diabetes, hypertension, renal insufficiency, cardiac disease, pulmonary disease, stroke, and cirrhosis may be more common. Typically, patients present with upper gastrointestinal bleeding, and hematemesis or melena is seen in up to $90 \%$ of cases. Herein we present 3 cases of AEN in critically ill patients. We also provide a review of the literature to highlight what is currently known about this relatively uncommon esophageal disease.
\end{abstract}

(C) 2019 The Author(s)

Published by S. Karger AG, Basel 


\section{Introduction}

Acute esophageal necrosis (AEN) or acute necrotizing esophagitis is a poorly described entity in the medical literature. Once thought to be extremely rare with an estimated prevalence of up to $0.2 \%$ in autopsy series, AEN is now more frequently diagnosed, perhaps due to the widespread availability and utilization of endoscopy. The incidence of AEN appears to be more than 4 times higher in men than in women, and patients have a mean age of 68 years at diagnosis. Classically, this condition is characterized by a striking endoscopic finding of diffuse circumferential black mucosa in the distal esophagus that abruptly stops at the gastroesophageal junction. The pathogenesis of AEN is unclear, but mucosal ischemia and injury due to gastric content reflux may be inciting events. Most investigators have described a "two-hit" hypothesis where there is an initial event that consists of a low-flow vascular state and altered reparative ability of the mucosal barrier systems present in malnourished and debilitated physiological states, which then predisposes the esophageal mucosa to a severe topical injury (i.e., by reflux of acid and pepsin). Upper gastrointestinal bleeding is the most common clinical presentation. Other manifestations include epigastric pain, retrosternal chest discomfort, and dysphagia. Our 3 cases of AEN were diagnosed in critically ill diabetic patients who developed hematemesis and melena.

\section{Case Report}

\section{Case 1}

A 69-year-old male with type 2 diabetes mellitus and a kidney transplant due to end-stage renal disease maintained on immunosuppressive therapy was admitted with vomiting and abdominal pain secondary to diabetic ketoacidosis complicated by a myocardial infarction. He received crystalloids, insulin therapy, antiplatelets, and heparin infusion. Subsequently the patient developed multiple episodes of hematemesis, for which he received appropriate resuscitation. A bedside upper endoscopy was performed to reveal a blackened esophagus, beginning at $25 \mathrm{~cm}$ and extending distally to end abruptly at the gastroesophageal junction (Fig. 1). Biopsies showed necrotic debris without viral inclusion bodies or fungal hyphae (Fig. 2). A repeat endoscopy was performed after adequate hemodynamic stabilization, which disclosed partial healing of the esophageal mucosa. The patient was subsequently discharged from the hospital in a stable condition without any long-term sequelae.

\section{Case 2}

A 74-year-old male with a history of type 2 diabetes mellitus, coronary artery disease, and peripheral vascular disease presented to the hospital with right lower extremity pain due to acute limb ischemia requiring femoropopliteal bypass surgery. The postoperative course was complicated by hypovolemic shock and a significant drop in hemoglobin. Upper endoscopy revealed AEN, starting at the mid esophagus with an abrupt cutoff at the gastroesophageal junction (Fig. 3). No biopsies were taken because of anticoagulation. The patient was conservatively managed with IV proton pump inhibitors and volume resuscitation to full clinical recovery. The patient refused a repeat esophagogastroduodenoscopy, but he recovered without any complications and was discharged to a nursing home. He is being followed at an outpatient clinic without any long-term complications. 
Case 3

A 79-year-old female with a history of thoracic aortic aneurysm, atrial fibrillation on Coumadin, and hypertension was admitted for syncope. The hospital course was complicated by pulmonary embolism, pneumonia, and acute respiratory failure requiring intubation and mechanical ventilation. The gastroenterology team was consulted due to hematemesis, and the patient was found to have extensive esophageal necrosis with mucosal flaps involving the middle and distal thirds of the esophagus, raising the possibility of full-thickness esophageal necrosis (Fig. 4). Biopsies were not taken to avoid bleeding because of anticoagulation and esophageal perforation. The patient died after a few days during the same hospitalization, likely from rupture of the thoracic aortic aneurysm.

\section{Discussion}

Goldenberg et al. [1] reported the very first endoscopic description of AEN in 1990 in a postoperative patient who developed a long esophageal ischemic stricture requiring esophagectomy. This clinical entity has been traditionally reported with a clinical incidence ranging from 0 to $0.2 \%$ in autopsy series [2] and $0.2 \%$ described in a prospective study [3]. It has a male predominance $(81 \%)$, with the patients having an average age of 67 years at diagnosis [4], although there are cases of disease occurrence in younger patients who are critically ill and have multiple comorbidities. The exact prevalence might be underestimated due to the subclinical presentation, delay in performing endoscopy due to the patients' medical condition, or early availability of bedside equipment, a brief period of ischemic insult, and early mucosal healing $[5,6]$.

AEN occurs due to a combination of various underlying risk factors with superimposed severe hemodynamic compromise, including shock of any etiology, gastric outlet obstruction, alcohol abuse, diabetes, hypoproteinemia, malignancy, renal insufficiency, chronic respiratory disease, cardiac failure, a hypercoagulable state, cirrhosis, an externally compressing hematoma, trauma, and major surgery [3].

Many theories have been proposed to explain the pathogenesis of this clinical entity. A recent case series revealed that nearly $90 \%$ of the patients have hyperglycemia [6], and a few studies reported that diabetic ketoacidosis was associated with AEN [7, 8], as also described in one of our patients. Transient nonobstructive gastropathy seen with an increased blood glucose concentration [9] or due to acute alcohol intoxication [10] could be implicated in the pathogenesis of AEN. Gastroesophageal reflux secondary to gastric outlet obstruction syndrome from gastric volvulus, a duodenal ulcer, pylorus obstruction, or abdominal surgery is a possible primary insult. Lacy et al. [11] found that two-thirds of their patients with AEN had some abnormality in the duodenum, including duodenal ulcers, severe duodenitis, or an abnormal pylorus, at endoscopy or autopsy. It is postulated that exposure of the distal segment of the esophagus to refluxate consisting of gastric acid, bile, and pepsin causes a decline in local esophageal blood flow causing initial injury and impairs the healing process.

A poor nutritional status coupled with vascular insufficiency with superimposed severe hemodynamic instability and hyperglycemia leads to diminished blood flow, mucosal buffering, impaired protective barriers, and corruption of the intrinsic repair mechanisms [3]. It is typically seen in critically ill patients with multiple comorbidities and transient low-flow states causing a variable degree of esophageal necrosis ranging from superficial mucosal ulceration to full-thickness necrosis of the entire esophagus, causing stricture formation and occasionally requiring esophagectomy. 
The most common presentation is upper gastrointestinal bleed in patients with a cardiovascular event or shock of any etiology. Notable symptoms may include epigastric pain, vomiting, dysphagia, fever, nausea, and syncope. It can also have an atypical presentation like abdominal distention and vomiting [12], described as a postmortem finding in a 17-year-old girl, and one report described an asymptomatic black esophagus in a cancer patient during a percutaneous endoscopic gastrostomy tube placement [13].

A biopsy is usually recommended but not required for a diagnosis of AEN. However, if taken, the sample should be sent for bacterial, fungal, and viral culture to exclude superimposed infections. The diagnosis of black esophagus requires the exclusion of other causes such as ingestion of caustic materials and should be based on histological examination [14]. Special care should be taken to evaluate for the presence of multinucleated giant cells or viral inclusion bodies, particularly in immunocompromised patients. Differential diagnoses include malignant melanoma, acanthosis nigricans, esophagitis dissecans superficialis, coal dust deposition, pseudomelanosis, and melanocytosis of the esophagus. AEN carries a mortality risk of about 38\%. Hence, increased awareness of this syndrome is of utmost importance to take appropriate measures and prevent complications. Upper gastrointestinal bleeding in a critically ill patient with multiple medical conditions, hemodynamic compromise, multiorgan dysfunction, alcohol intoxication, diabetic ketoacidosis, vasculopathy, hypercoagulable states, malignancy, or organ transplantation should raise the possibility of AEN among other diagnoses.

Management is focused on treating the underlying illness and involves fluid resuscitation, gastric acid suppression, and parenteral nutrition when necessary. Antibiotic therapy in AEN is controversial. Some authors believe that antibiotic therapy may even predispose the patient to develop black esophagus [15]. On the other hand, it is important to use appropriate antibiotics to cover the specific pathogen identified in a biopsy specimen and for other infectious causes associated with the development of black esophagus [3]. The various complications associated include strictures or stenosis (10.2\%), mediastinitis/abscess formation (5.7\%), perforation $(6.8 \%)$, and death $(31.8 \%)$. AEN has a very poor prognosis, with a mortality rate as high as $31.8-50 \%$, likely due to underlying medical comorbidities $[3,16]$. However, mortality primarily due to esophageal disease or necrosis is reported to be around $6 \%$.

In conclusion, AEN should be considered as an essential cause of upper gastrointestinal bleeding especially in an elderly immunosuppressed individual with critical illness and in younger adults with alcohol abuse. AEN must be recognized early and managed aggressively to improve clinical outcomes and thus decrease the mortality associated with the underlying disease.

\section{Statement of Ethics}

Approval from the ethics committee was not required for this case report. Informed consent was obtained from the patients for publication of this case report and any accompanying images.

\section{Disclosure Statement}

None of the authors has any financial conflicts of interest to declare. 


\section{Author Contributions}

Hafiz Khan: patient management, writing of the manuscript, literature research; Moiz Ahmed: literature research, editing of the manuscript; Magda Daoud: literature research, editing of the manuscript; Jobin Philipose: editing of the manuscript; Saba Ahmed: editing of the manuscript; Liliane Deeb: study mentor, final approval of the manuscript to be submitted. Article guarantor: Jobin Philipose.

\section{References}

1 Goldenberg SP, Wain SL, Marignani P. Acute necrotizing esophagitis. Gastroenterology. 1990 Feb;98(2): 493-6.

2 Etienne JP, Roge J, Delavierre P, Veyssier P. [Esophageal necrosis of vascular origin]. Sem Hop. 1969 May;45(23):1599-606.

3 Ben Soussan E, Savoye G, Hochain P, Hervé S, Antonietti M, Lemoine F, et al. Acute esophageal necrosis: a 1-year prospective study. Gastrointest Endosc. 2002 Aug;56(2):213-7.

4 Gurvits GE, Shapsis A, Lau N, Gualtieri N, Robilotti JG. Acute esophageal necrosis: a rare syndrome. J Gastroenterol. 2007 Jan;42(1):29-38.

5 Gurvits GE. Black esophagus: acute esophageal necrosis syndrome. World J Gastroenterol. 2010 Jul;16(26):3219-25.

6 Gurvits GE, Cherian K, Shami MN, Korabathina R, El-Nader EM, Rayapudi K, et al. Black esophagus: new insights and multicenter international experience in 2014. Dig Dis Sci. 2015 Feb;60(2):444-53.

7 Im JH, Kim MS, Lee SY, Kim SH, Hong SB, Nam M, et al. A case of acute esophageal necrosis in a patient with diabetic ketoacidosis. Korean J Med. 2012;83(1):117-21.

8 Kim YH, Choi SY. Black esophagus with concomitant candidiasis developed after diabetic ketoacidosis. World J Gastroenterol. 2007 Nov;13(42):5662-3.

9 Fraser RJ, Horowitz M, Maddox AF, Harding PE, Chatterton BE, Dent J. Hyperglycaemia slows gastric emptying in type 1 (insulin-dependent) diabetes mellitus. Diabetologia. 1990 Nov;33(11):675-80.

10 Endo T, Sakamoto J, Sato K, Takimoto M, Shimaya K, Mikami T, et al. Acute esophageal necrosis caused by alcohol abuse. World J Gastroenterol. 2005 Sep;11(35):5568-70.

11 Lacy BE, Toor A, Bensen SP, Rothstein RI, Maheshwari Y. Acute esophageal necrosis: report of two cases and a review of the literature. Gastrointest Endosc. 1999 Apr;49(4 Pt 1):527-32.

12 Eren B, Turkmen N, Fedakar R. Black esophagus: a rare autopsy case. Bratisl Lek Listy. 2010;111(7):414-5.

13 Rejchrt S, Douda T, Kopácová M, Siroký M, Repák R, Nozicka J, et al. Acute esophageal necrosis (black esophagus): endoscopic and histopathologic appearance. Endoscopy. 2004 Dec;36(12):1133.

14 Tsokos M, Herbst H. Black oesophagus: a rare disorder with potentially fatal outcome. A forensic pathological approach based on five autopsy cases. Int J Legal Med. 2005 May;119(3):146-52.

15 Mangan TF, Colley AT, Wytock DH. Antibiotic-associated acute necrotizing esophagitis. Gastroenterology. 1990 Sep;99(3):900.

16 Grudell AB, Mueller PS, Viggiano TR. Black esophagus: report of six cases and review of the literature, 19632003. Dis Esophagus. 2006;19(2):105-10. 


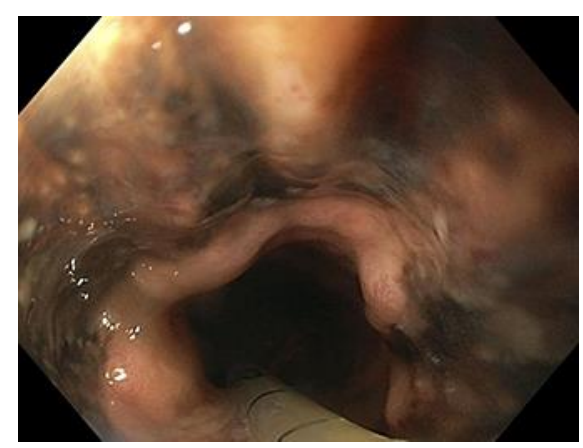

Fig. 1. Esophagogastroduodenoscopy revealed a black esophagus in the distal part of the esophagus, ending abruptly at the gastroesophageal junction.

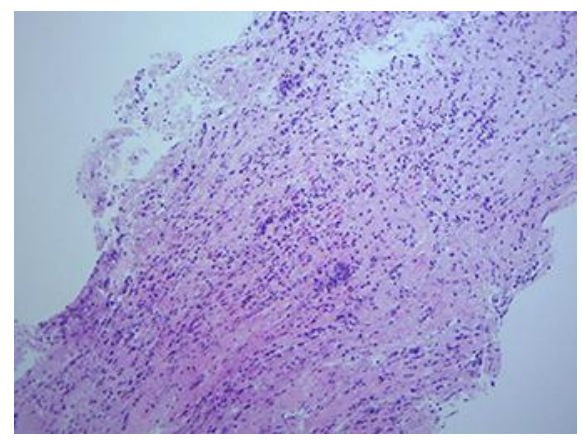

Fig. 2. Esophageal biopsy showing a necrotic esophagus with inflammatory infiltrate. H\&E. Original magnification, $\times 100$.

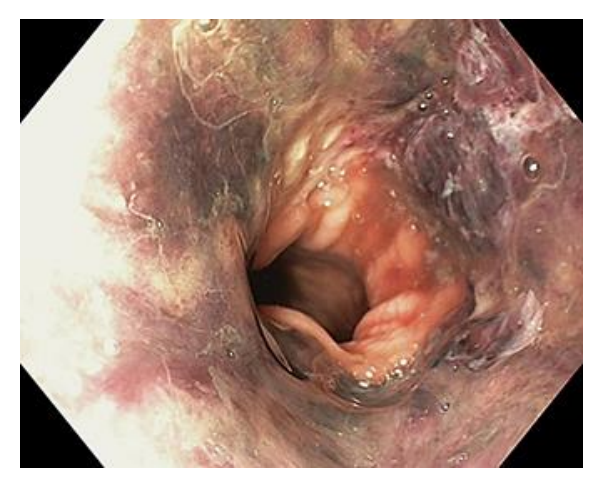

Fig. 3. Esophagogastroduodenoscopy showing diffuse and circumferential esophageal necrosis. 


\begin{tabular}{|c|c|c|}
\hline \multirow{3}{*}{$\begin{array}{r}\text { Case Reports in } \\
\text { Gastroenterology }\end{array}$} & \multirow{2}{*}{\multicolumn{2}{|c|}{ Case Rep Gastroenterol 2019;13:25-31 }} \\
\hline & & \\
\hline & DOI: $10.1159 / 000496385$ & $\begin{array}{l}\text { (c) } 2019 \text { The Author(s). Published by S. Karger AG, Basel } \\
\text { www.karger.com/crg }\end{array}$ \\
\hline
\end{tabular}

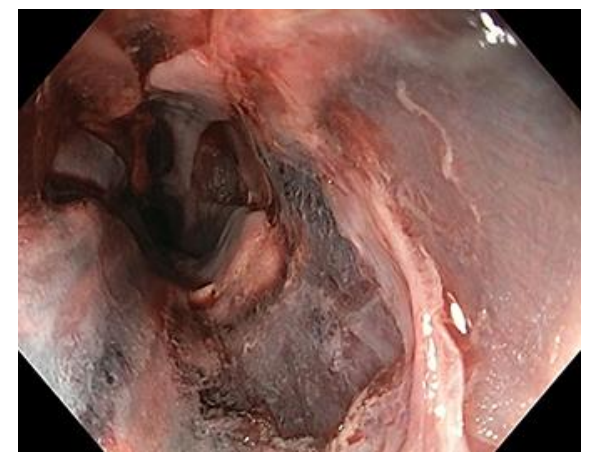

Fig. 4. Esophagogastroduodenoscopy showing extensive esophageal necrosis with mucosal flaps involving the middle and distal thirds of the esophagus, raising the possibility of full-thickness esophageal necrosis. 